\section{Autosomal translocation associated with premature ovarian failure}

EDITOR-Although the average age of menarche has decreased over the last century, the mean age of menopause appears to be invariant with time and race and occurs at approximately 50 years. The loss of functional follicles occurring in women under the age of 40 is defined as premature ovarian failure. It occurs in about $1-2 \%$ of women, ${ }^{1}$ in some as early as their teens. Before the onset of premature ovarian failure, most women appear to have a normal menstrual history, age of menarche, and fertility. ${ }^{2}$ Unexplained premature ovarian failure is clinically recognised as amenorrhoea with low levels of oestrogen and raised levels of luteinising hormone $(\mathrm{LH})$ and follicle stimulating hormone (FSH) occurring before the age of 40 .

Premature ovarian failure may have a chromosomal, genetic, enzymatic, iatrogenic, autoimmune, or infectious aetiology. In approximately $5 \%$ of women with premature ovarian failure there is a significant family history of early menopause. ${ }^{3}$ However, in most cases, no known cause has been identified. ${ }^{2}$ Genetic causes have been suggested, and a range of candidate loci have been identified. These regions are currently under investigation to determine the underlying basis of ovarian failure.

The proband (III.10), a 33 year old woman, presented for fertility care. She is the only woman in a sibship of three and her pedigree is shown in fig 1 . Her brothers have fathered healthy children and each of their wives has had one early spontaneous miscarriage. Her mother (II.3) had an uncomplicated gynaecological history with no menstrual disturbances and underwent an easy menopause at the age of 55 years. She had an early miscarriage and three successful pregnancies, which were separated by four and nine years respectively. The proband's paternal grandmother (I.2) had two healthy pregnancies two years apart and was described as having had a problematical menopause in her early sixth decade. There is no family history of ill health or disability. There is a suggestion that some of the males in the family could be subfertile, as they have had small families and the children have been widely spaced.

The proband experienced menarche at the age of 14 and her menses were irregular. She suffered secondary amenorrhoea at the age of 16 years with markedly increased FSH and LH levels. She has been treated with hormone replacement therapy for the past 10 years, which has resulted in cyclical bleeding. She has remained anovulatory.

The karyotype of the proband showed a translocation between chromosomes 2 and 15: 46,XX,t $(2 ; 15)$ (q32.3; q13.3). Fig 2 shows the breakpoints of the chromosomes. On further investigation of her family, her father was found to have the same translocation. Her brothers have declined cytogenetic testing at this time.

In most cases of POF, no cause can be identified. ${ }^{2}$ Iatrogenic agents, such as chemotherapy or radiotherapy, are known to reduce follicle numbers. Chromosomal abnormalities have been described, especially those that involve the $\mathrm{X}$ chromosome. ${ }^{4-10}$ These include XO (Turner's syndrome), 47, XXX, X chromosome mosaics (45,XO/ 46,XX, 46,XX/47,XXX, 45,XO/46,XX/47,XXX), $\mathrm{X}$ chromosome deletions and inversions, and $\mathrm{X}$;autosome balanced translocations. A family history has been noted in some women with POF, approximately $5 \%,{ }^{3}$ that would suggest an inherited defective gene. Several candidate genes have been suggested to cause both familial and sporadic $\mathrm{POF}$. These include genes on the $\mathrm{X}$ chromosome

Balanced translocation

Translocation; premature ovarian failure

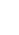

III

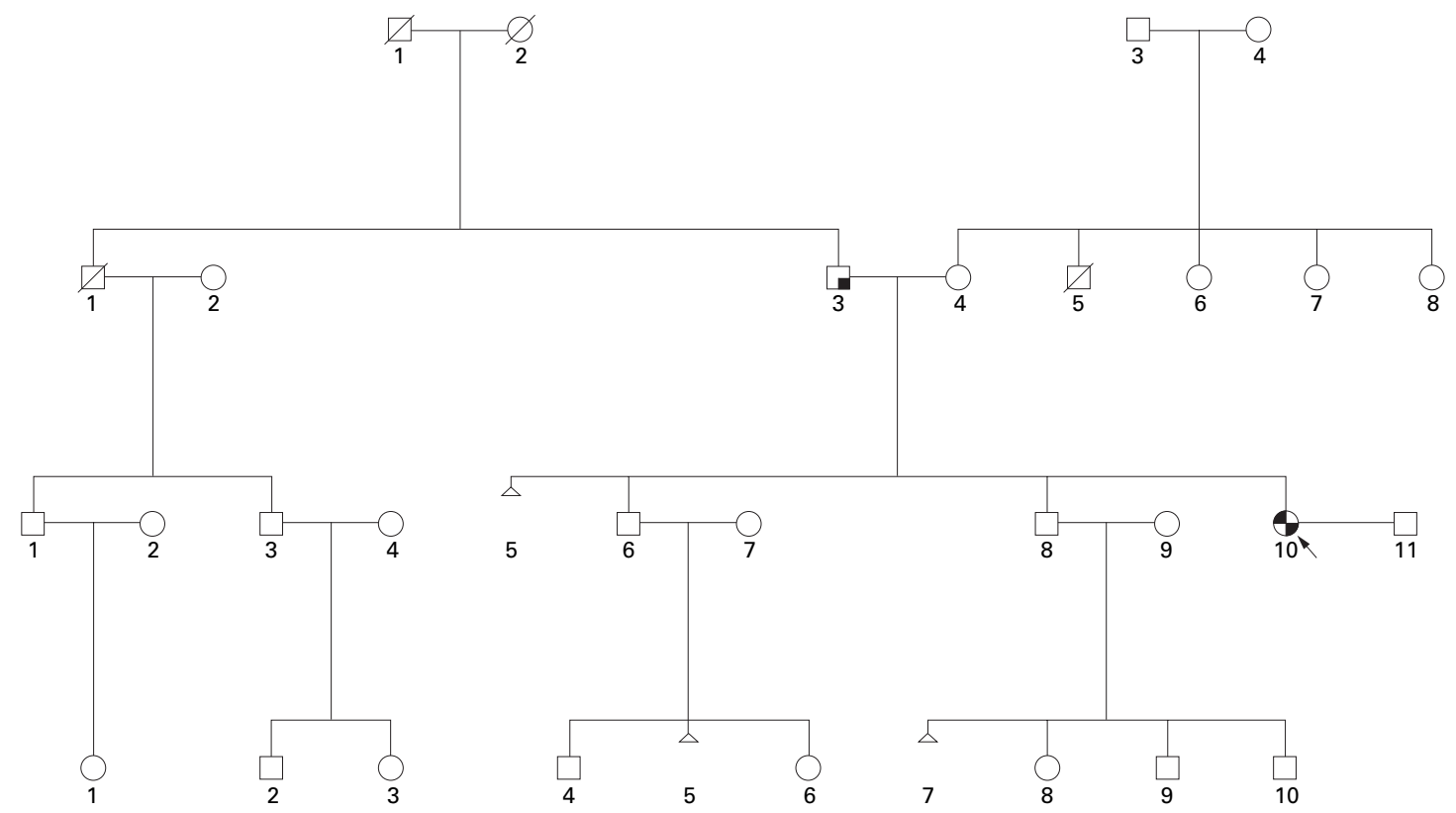

IV

Figure 1 Pedigree of the family. 


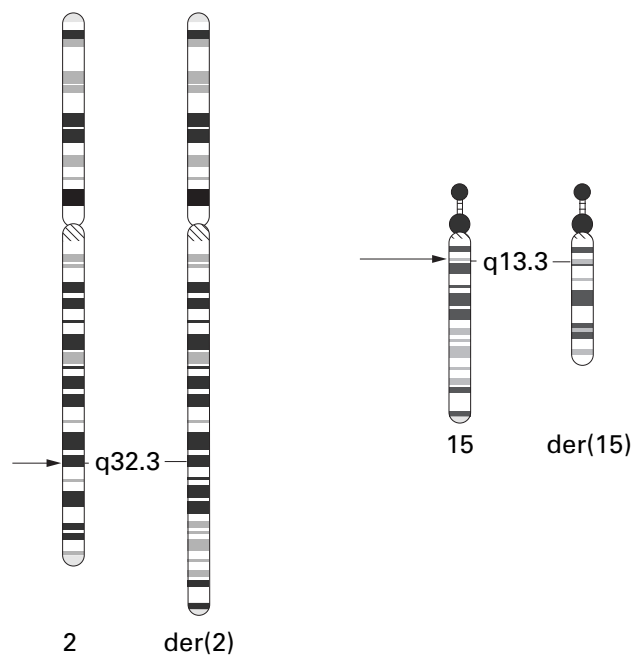

Figure 2 Ideogram of chromosomes 2 and 15 showing the breakpoints at $2 q 32.3$ and $15 q 13.3$.

(POF1, POF2, FMR1), chromosome 3q22-3q23 in families with blepharophimosis, ${ }^{11}$ and the FSH receptor gene. ${ }^{12}$

Autoimmune causes have been suggested and it appears that $10-20 \%$ of women with POF have an autoimmune disease $^{3}$; however, its role remains controversial. Infectious routes have been suggested, particularly mumps oophoritis, but this appears to be a rare event. Biochemical causes, such as galactosaemia, enzyme deficiencies, and signal defects, have also been noted.

We have identified a proband who has experienced menarche at the age of 14 , two years of irregular menstruation, and ovarian failure at the age of 16 . The family has two interesting features. First, there have been only two females born in three generations (compared to 10 males). One of those females had premature menopause at the age of 16. It is interesting to note that the other female in the family was born three months prematurely. It remains to be seen whether she will also develop premature menopause. Second, the children in each family are widely spread, approximately four or five years between live births. This could be because of undiagnosed miscarriages or possibly subfertility in the males if they were carriers of the translocation.

It may be of significance that she has a translocation between two autosomes, chromosomes 2 and 15. Autosomal translocations are uncommon in women with POF and reports of translocations are of X;autosome balanced translocations, with no common autosomal breakpoint. To the best of our knowledge, only three autosomal translocations in women with premature ovarian failure have been published. Two of these were identified by Hens $e t a l^{13}$ and were $46, \mathrm{XX}, \mathrm{t}(2 ; 11)$ and $45, \mathrm{XX}, \mathrm{t}(13 ; 14)$. It is interesting to note that the patient with the $2 ; 11$ translocation may have experienced early menopause following bilateral oophorectomy after endometriosis, so it is difficult to ascertain whether the translocation was associated with premature ovarian failure. A second translocation between chromosomes 13 and $14,45, \mathrm{XX}, \mathrm{t}(13,14)$, has recently been reported in a 19 year old Japanese woman with secondary amenorrhoea. ${ }^{14}$

The translocation that we describe here has been inherited from the proband's father who has no clinical problems and is clearly fertile, but as the children are spaced several years apart there is a possibility that he may be subfertile. However, it is plausible that a gene at one of the breakpoints of this translocation may be causal in this case of premature ovarian failure. Both translocation breakpoints lie in close proximity to interesting genes. The breakpoint at 15q11 localises to the Prader-Willi/ Angelman disease locus, ${ }^{15}$ which is associated with hypogonadism. The translocation breakpoint on $2 \mathrm{q} 32.3$ lies beside the inhibin alpha gene, which has been localised to 2 q33-qter.

Future studies will revolve around analysis of the translocation breakpoint to determine whether it has disrupted the inhibin alpha gene or Prader-Willi/Angelman locus. We plan to study this patient further using cytogenetic methods (FISH mapping of YAC and cosmid clones) to refine and localise the translocation breakpoints and clone the associated genes. The inhibin alpha gene locus is a promising candidate gene for premature ovarian failure and molecular studies will determine whether this gene is a target for mutations. We are grateful to Karen Claxton, Alice George, Paul Oei, and Beverley Couper
for cytogenetic analysis. We would like to thank the University of Auckland Research Committee, the Health Research Council of New Zealand, and the Auckland Medical Research Foundation for supporting this project.

$$
\begin{array}{r}
\text { KAREN A BURTON } \\
\text { CYNTHIA C VAN EE* } \\
\text { KIM PURCELL } \\
\text { INGRID WINSHIP }
\end{array}
$$
ANDREW N SHELLING*

${ }^{\star}$ Research Centre in Reproductive Medicine, Department of Obstetrics and Gynaecology, National Women's Hospital, University of Auckland, Auckland, New Zealand

†Cytogenetics Department, Starship Children's Hospital, Private Bag 92024, Auckland, New Zealand

$\ddagger$ Department of Molecular Medicine, School of Medicine, University of Auckland, Auckland, New Zealand

Correspondence to: Dr Shelling, a.shelling@auckland.ac.nz

1 Coulam CB, Adamson SC, Annegers JF. Incidence of premature ovarian failure. Obstet Gynecol 1986;67:604-6

2 Anasti JN. Premature ovarian failure - an update. Fertil Steril 1998;70:1-15. 3 Conway GS. Premature ovarian failure. Curr Opin Obstet Gynecol 1997;9:202-6

4 Bione S, Sala C, Manzini C, et al. A human homologue of the Drosophila melanogaster diaphanous gene is disrupted in a patient with premature ovarian failure: evidence for conserved function in oogenesis and implications for human sterility. Am f Hum Genet 1998;62:533-41.

5 Davison RM, Quilter CR, Webb J, et al. A familial case of X chromosome deletion ascertained by cytogenetic screening of women with premature deletion ascertained by cytogenetic screening
ovarian failure. Hum Reprod 1998;13:3039-41.

6 Fitch N, De Saint Victor J, Richer CZ, Pinsky L, Sitahal S. Premature menopause due to a small deletion in the long arm of the $\mathrm{X}$ chromosome: a report of three cases and a review. Am f Obstet Gynecol 1982;142:968-72.

7 Krauss CM, Turksoy RN, Atkins L, McLaughlin C, Brown LG, Page DC. Familial premature ovarian failure due to an interstitial deletion of the long arm of the X chromosome. N Engl F Med 1987;317:125-31.

8 Powell CM, Taggart RT, Drumheller TC, et al. Molecular and cytogenetic studies of an $\mathrm{X}$ autosome translocation in a patient with premature ovarian failure and review of the literature. Am $\mathcal{F}$ Med Genet 1994;52:19-26.

9 Sala C, Arrigo G, Torri G, et al. Eleven X chromosome breakpoints associated with premature ovarian failure (POF) map to a 15-Mb YAC contig spanning Xq21. Genomics 1997;40:123-31.

10 Skibsted L, Westh H, Niebuhr E. X long-arm deletions: a review of non-mosaic cases studied with banding techniques. Hum Genet 1984;67:1-

11 Amati P, Gasparini P, Zlotogora J, et al. A gene for premature ovarian failure associated with eyelid malformation maps to chromosome 3q22-q23. Am $\mathcal{f}$ Hum Genet 1996;58:1089-92.

12 Aittomaki K, Lucena JLD, Pakarinen P, et al. Mutation in the follicle-stimulating hormone receptor gene causes hereditary hypergonadotropic ovarian failure. Cell 1995;82:959-68.

13 Hens L, Devroey P, Van Waesberghe L, et al. Chromosome studies and fertility treatment in women with ovarian failure. Clin Genet 1989;36:81-91.

14 Kawano Y, Narahara H, Matsui N, Miyakawa I. Premature ovarian failure associated with a Robertsonian translocation. Acta Obstet Gynecol Scand 1998;77:467-9.

15 Butler MG, Meaney FJ, Palmer CG. Clinical and cytogenetic survey of 39 individuals with Prader-Labhart-Willi syndrome. Am $f$ Med Genet 1986;23:793-809. 